\title{
Sleep disturbance and psychological distress are associated with functional dyspepsia based on Rome III criteria
}

\author{
Yong $\mathrm{Li}^{1 \dagger}$, Yaoyao Gong ${ }^{2 \dagger}$, Yinghui $\mathrm{Li}^{4}$, Danjun $\mathrm{He}^{1}$, Yuqin $\mathrm{Wu}^{1}$, Haofei Wang ${ }^{1}$, Xiaoyin Cong ${ }^{1}$, Muxin Wei ${ }^{3^{*}}$
} and $\operatorname{Lin} \operatorname{Lin}^{2^{*}}$

\begin{abstract}
Background: Functional dyspepsia (FD) is considered a bio-psychosocial disorder. The role of psychosocial factors in FD pathogenesis remains unclear.

Methods: This study evaluated sleep quality and mood symptoms in patients with FD, assessing the associations of FD severity, disordered sleep, and psychological symptoms. One-hundred-and-fifteen adult patients with typical FD symptoms were enrolled alongside 61 healthy volunteers. Rome III criteria were used to evaluate FD symptoms; sleep disorder was assessed with the Pittsburgh Sleep Quality Index (PSQI), and Symptom Checklist-90-Revised (SCL-90R) was utilized to determine the status of depression, anxiety and other psychological symptoms.
\end{abstract}

Results: PSQI scores and nine symptomatic dimensions of SCL-90R were significantly higher in FD patients than in controls. Multiple logistic regression indicated that lower BMI, lower level of education, and sleep disturbance were independently associated with FD and FD subgroups. Hostility and phobic anxiety were independent risk factors for FD. Further analysis showed that hostility was an independent risk factor for both FD subgroups, and somatization and additional psychiatric symptoms for epigastric pain syndrome.

Conclusions: We found that FD was associated with sleep disorder and psychopathological factors. These findings suggest that implementing sleeping and/or psychological therapies may help reduce FD symptoms.

Keywords: Functional dyspepsia, Sleep disturbance, Psychological factors, Rome III criteria

\section{Background}

Functional dyspepsia (FD), one of the most common functional gastrointestinal disorders (FGIDs), is defined as pain and/or discomfort centered in the upper abdomen in the absence of obvious organic abnormalities [1]. The Rome III Consensus divided FD into two subgroups: epigastric pain syndrome (EPS, characterized by epigastric pain and burning) and postprandial distress syndrome (PDS, characterized by postprandial fullness and early satiety). FD is currently considered a bio-psychosocial disorder as a result of impaired motor function, Helicobacter

\footnotetext{
* Correspondence: weimuxin@njmu.edu.cn; lin9100@aliyun.com

${ }^{+}$Yong Li and Yaoyao Gong contributed equally to this work.

${ }^{3}$ Department of Traditional Chinese Medicine, the First Affiliated Hospital of

Nanjing Medical University, Nanjing 210029, China

${ }^{2}$ Department of Gastroenterology, the First Affiliated Hospital of Nanjing

Medical University, Nanjing 210029, China

Full list of author information is available at the end of the article
}

pylori infection, heightened visceral sensitivity, central nervous system disturbance, and unhealthy lifestyle [2]. Due to the differences in dietary habits, lifestyle, and Helicobacter pylori infection prevalence, the symptoms, epidemiology, pathogenetic factors, and management differ between Asian and Western FD patients [3].

Mounting evidence suggests that psychological distress is associated with FD; however, very few studies have assessed psychological factors that contribute to FD development. A Swedish 10-year-follow-up study of FD patients applying the Rome III definition showed an association of anxiety but not depression with FD [4]; meanwhile, a retrospective study based on the Rome III definition revealed that postprandial distress syndrome but not epigastric pain syndrome is associated with somatization, depression, and phobia [5].

(c) The Author(s). 2018 Open Access This article is distributed under the terms of the Creative Commons Attribution 4.0 International License (http://creativecommons.org/licenses/by/4.0/), which permits unrestricted use, distribution, and 
Besides psychological factors, sleep disorder is a common phenomenon in FD patients and may influence the severity of dyspepsia symptoms [6]. In addition, sleep disturbance, anxiety, and depression are usually closely related; previous studies also found that sleep disturbance in FD patients appears to be associated with higher levels of anxiety [6]. However, whether sleep disorder or various psychological factors are independently associated with the development and severity of FD remains unclear.

In the present study, we used an integrated questionnaire consisting of the major dyspepsia symptom scale, Symptom Checklist-90-Revised (SCL-90R), and Pittsburgh Sleep Quality Index (PSQI) to assess FD severity, psychological health and sleeping condition in patients meeting Rome III criteria for FD. The study aimed to explore the associations of psychological distress or sleep disturbance with FD and FD subgroups based on Rome III criteria.

\section{Methods}

\section{Participants and setting}

Adult outpatients from the digestive and psychological departments of First Affiliated Hospital of Nanjing Medical University meeting ROME III criteria for FD between July 2015 and May 2016 were recruited for this study. The included patients have undergone an upper endoscopic test to exclude organic digestive diseases that might have explained the observed symptoms. Local adult volunteers without known gastrointestinal or psychological disorders, who underwent gastric endoscopy as regular medical examination, were recruited as healthy controls. All patients and controls underwent detailed history taking. All subjects with the following conditions were excluded: (a) a history of upper gastrointestinal tract surgery, (b) a history of ulcerative disease or malignancy, (c) current treatment with non-steroidal anti-inflammatory drugs (NSAIDs), (d) use of monoamine oxidase inhibitors or selective serotonin reuptake inhibitors, (e) pregnancy for women, (f) pancreatitis or hepatobiliary disorders, and (g) physical or psychological impairments that prevented from completing the questionnaires. Patients with concomitant irritable bowel syndrome (IBS) symptoms but not meeting the ROME III criteria for IBS were not excluded.

\section{FD symptoms definition and Rome III diagnostic questionnare}

FD was defined as the presence of postprandial fullness/ early satiation or pain/burning more than once per week, in the last 3 months according to the Rome III criteria. To diagnose FD and evaluate the severity of dyspepsia related symptoms, the original Rome III functional dyspepsia module [1] was translated into Chinese, confirmed by two digestive disease experts, and scrutinized by two native Chinese speakers without medical background to ensure that the text was easily understandable. The severity of major dyspeptic symptoms (postprandial abdominal fullness or discomfort, early satiety, epigastric pain, and epigastric burning) was rated on a 7 -point Likert scale ( 0 , absent; 1 , hardly any; 2 , mild; 3 , moderate; 4 , moderately severe; 5 , severe; 6 , very severe).

\section{Sleep quality assessment (PSQI)}

A Chinese version of the PSQI questionnaire was used to assess the patient's recent history of sleep quality. The PSQI questionnaire consisted of 19 self-rating items that can be categorized into seven components, including subjective sleep quality, sleep latency, sleep duration, habitual sleep efficiency, sleep disturbance, use of sleep medication, and daytime dysfunction. The score of each component score was rated from 0 to 3. The sum of these seven component scores provided a global PSQI score, which ranged from 0 to 21 . Higher scores indicate poorer sleep. The Chinese Version of PSQI was translated and validated by Liu et al. [7]. In that study, the internal consistency Cronbach's $\alpha$ was 0.84 , the split-half reliability was 0.87 , and the 2 -week test-retest reliability was 0.81 .

\section{Evaluation of psychiatric distress and lifestyle factors}

Psychiatric distress was estimated using the Chinese version of SCL-90R [8]. The SCL-90R is a self-reporting, clinical symptom rating scale consisting of 90 items. Responses indicate symptoms associated with 9 symptom dimensions, which included somatization (distress arising from perceptions of bodily dysfunction), obsessive-compulsive (thoughts, impulses and actions that are experienced as irresistible and unremitting), interpersonal sensitivity (feelings of inferiority or inadequacy), depression, anxiety, hostility (thoughts, feelings and actions that are characteristic of the negative affect state of anger), phobic anxiety (irrational fear of specific situations or persons), paranoid ideation (paranoid behavior as fundamentally a disordered mode of thinking), and psychoticism [9]. Additionally, a global symptom score is calculated. The Chinese-version SCL-90R questionnaire [8] with established reliability and validity is widely used in measuring psychological distress in Chinese clinical practice and research. In a recent study carried out in patients with alopecia areata, the internal consistency Cronbach's $\alpha$ was 0.98 and split-half coefficient was 0.95 [10]. Demographic data and lifestyle factors (including age, gender, marital status, body mass index (BMI), education level, smoking, and consumption of alcohol were recorded in all patients and controls). Tobacco and alcohol use was divided into never/rare and regular use (more than once a week). Each questionnaire was completed individually and independently by the participant. 


\section{Data analysis}

Data were assessed with Statistical Package for the Social Sciences (SPSS) for Windows, version 13.0. Measurement data are mean \pm standard deviation (SD). Student $t$ test and one way analysis of variance (ANOVA) were used to statistically assess demographic variables such as weight, height, and BMI. Various sleep disorder parameters and psychological factors between FD patients and healthy controls were also assessed by Student $t$ test. The association of total PSQI score and FD symptom severity score was assessed by Spearman correlation analysis. Risk factors for dyspepsia were initially explored by univariate analysis. Those with $P<0.05$ were then entered into a multivariate analysis. Independent risk factors for dyspepsia were subsequently determined by backward elimination logistic regression. Data were expressed as odds ratio (OR) with 95\% confidence interval $(95 \% \mathrm{CI}) . P<0.05$ was considered statistically significant.

\section{Results}

\section{Response rate and demographics}

Of the 263 subjects eligible for inclusion, a total of 224 (85.1\%) individuals agreed to participate in the study. However, 109 individuals did not complete the questionnaires because of low education level or desire to withdraw. Therefore, a total of 115 FD outpatients completed questionnaires, yielding a response rate of $43.7 \%$. Meanwhile, 61 healthy controls were enrolled. The mean age of the control population was $41.36 \pm 12.32$ years; $80.3 \%$ of control individuals were female.

Table 1 describes the basic demography of the study population. The mean age of interviewees was $41.72 \pm$ 12.22 years, ranging from 17 to 61 years. A total of 143 $(81.3 \%)$ adults were female. There were no significant differences between the two groups in terms of age, gender, marital status, regular tobacco use, and regular alcohol intake. FD patients had lower BMI and level of education compared with the control group.

\section{FD symptoms}

Mean duration of FD symptoms was $52 \pm 50$ months, and the patients reported that FD symptoms were present $4.1 \pm 2.3$ days per week. Among the 115 FD participants, 87 (75.7\%) had symptoms consistent with EPS (including 61 individuals with pure EPS symptoms) and $54(47.0 \%)$ conformed to PDS (including 28 with pure PDS symptoms); 26 patients (22.6\%) reported dyspeptic symptoms compatible with both EPS and PDS.

\section{Sleep symptoms}

Average sleep durations in FD patients and healthy controls were $6.24 \pm 1.37$ and $6.87 \pm 1.05 \mathrm{~h}$, respectively $(P<0.05)$. Occasional sleep problems were common in both FD and control groups; indeed, 67.2 and $58.6 \%$ of FD patients and control participants, respectively, reported having sleep abnormality 1 to 3 days a month. Significantly higher PSQI scores were found in FD patients compared with controls $(10.49 \pm 3.38$ vs $6.77 \pm 2.77$, respectively; $P<0.01)$. In addition, as shown in Table 2, six parameters, including subjective sleep quality, sleep latency, sleep duration, sleep disturbance, use of sleeping medication, and daytime dysfunction showed remarkably higher scores in FD patients compared with controls.

\section{Association of Sleep Disturbance with FD symptoms}

To further investigate the association between overall sleep score and FD symptom score, we applied a Spearman regression analysis within patients with $\mathrm{FD}$. There was a significant correlation between total PSQI sleep score and overall FD symptom score $\left(r_{p}=0.63, P<0.01\right)$. A total of $61 \mathrm{FD}$ patients had a score above 11, with 5 having values $>15$, which reflects severe sleep disturbance in all domains.

Table 1 Basic demographics of the study population

\begin{tabular}{|c|c|c|c|}
\hline Characteristic & $\mathrm{FD}(n=115)$ & Controls $(n=61)$ & $P$ value \\
\hline Age (year) & $41.90 \pm 12.21$ & $41.36 \pm 12.32$ & 0.78 \\
\hline BMI & $23.46 \pm 2.22$ & $24.99 \pm 2.40$ & $0.00 *$ \\
\hline Gender Female (\%) & $94(81.7)$ & $49(80.3)$ & 0.82 \\
\hline \multicolumn{4}{|l|}{ Marital status } \\
\hline Single/widower/divorced (\%) & $21(18.5)$ & $6(10.0)$ & 0.14 \\
\hline Married (\%) & $94(81.7)$ & $54(90.0)$ & 0.15 \\
\hline Years of education (year) & $11.31 \pm 2.81$ & $13.95 \pm 4.04$ & $0.00^{*}$ \\
\hline Regular tobacco use (\%) & $42(36.5)$ & $22(36.7)$ & 0.98 \\
\hline Regular alcohol intake (\%) & $44(38.3)$ & $25(41.7)$ & 0.66 \\
\hline Duration of symptoms (mo) & $52 \pm 50$ & - & - \\
\hline Days per week with symptoms & $4.1 \pm 2.3$ & - & - \\
\hline
\end{tabular}

$B M I$ body mass index calculated as weight $(\mathrm{kg}) / \mathrm{height}\left(\mathrm{m}^{2}\right)$ ${ }^{*} P<0.05$ 
Table 2 PSQI scores in FD patients and healthy controls (mean \pm SD)

\begin{tabular}{lllllllll}
\hline Groups & $\begin{array}{l}\text { Subjective } \\
\text { sleep quality }\end{array}$ & $\begin{array}{l}\text { Sleep } \\
\text { latency }\end{array}$ & $\begin{array}{l}\text { Sleep } \\
\text { duration }\end{array}$ & $\begin{array}{l}\text { Habitual sleep } \\
\text { efficiency }\end{array}$ & $\begin{array}{l}\text { Sleep } \\
\text { disturbance }\end{array}$ & $\begin{array}{l}\text { Use of sleeping } \\
\text { medications }\end{array}$ & $\begin{array}{l}\text { Daytime } \\
\text { dysfunction }\end{array}$ & $\begin{array}{c}\text { Total score } \\
\text { FD }\end{array}$ \\
\hline HC & $1.94 \pm 0.61$ & $2.43 \pm 0.85$ & $1.40 \pm 1.11$ & $1.33 \pm 1.39$ & $1.81 \pm 0.51$ & $0.70 \pm 1.16$ & $0.75 \pm 0.66$ & $10.49 \pm 3.38$ \\
$t$ & $1.61 \pm 0.86$ & $1.60 \pm 1.13$ & $0.89 \pm 0.91$ & $1.08 \pm 1.08$ & $1.18 \pm 0.89$ & $0.21 \pm 0.41$ & $0.21 \pm 0.49$ & $6.77 \pm 2.77$ \\
$P$ & 2.678 & 5.065 & 3.298 & 1.306 & 5.110 & 4.019 & 6.102 & 7.830 \\
\hline
\end{tabular}

${ }^{*} P<0.05$

Moreover, there was a consistent, stepwise increase of FD symptom scores with increasing sleep scores (Fig. 1).

\section{Psychological symptoms}

To assess the associations of various psychological factors with FD development, we first compared ten symptomatic dimensions as well as total SCL-90R scores between FD patients and healthy controls. Interestingly, somatization, obsessive-compulsive, interpersonal sensitivity, depression, anxiety, hostility, phobic anxiety, psychoticism, additional items, and total score showed markedly higher levels in the FD group than in controls (Table 3).

To further identify which psychological factors were independent risk factors for FD, a multivariate logistic regression model was employed (Table 4). Hostility $(\mathrm{OR}=4.29,95 \% \mathrm{CI} 1.12-16.47, P<0.05)$ and phobic anxiety $(\mathrm{OR}=6.41,95 \% \mathrm{CI}=1.40-29.43, P<0.05)$ were independent risk factors for dyspepsia. However, no significant associations of symptomatic dimension scores with the FD symptom score were found.

\section{Independent risk factors for FD}

Besides hostility and phobic anxiety, lower BMI (OR = 0.75; 95\%CI 0.62-0.91; $P<0.05$ ), lower education levels (OR = 0.77 ; 95\%CI $0.67-0.89 ; P<0.001)$, and higher PSQI

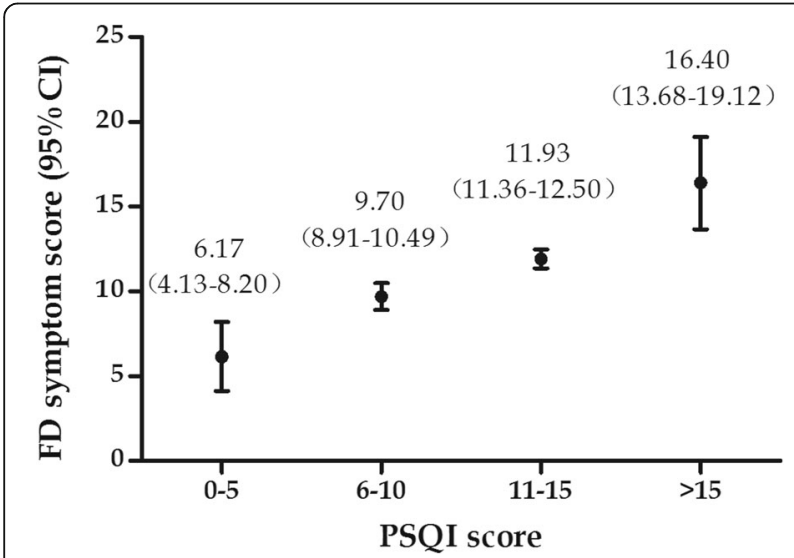

Fig. 1 Univariate association of PSQI score with FD symptom score. The FD symptom score increased stepwise with sleep score. The higher the sleep score, the more severe the sleep disturbance was score $(\mathrm{OR}=1.55 ; 95 \% \mathrm{CI} 1.30-1.84 ; P<0.001)$ were also independent risk factors for FD (Table 4).

\section{Independent risk factors for FD subgroups}

To assess the associations of each FD subgroup with psychiatric distress and sleep disorder, subgroup analysis was performed. EPS was independently associated with somatization, hostility and additional symptoms, while PDS was independently associated with hostility. Both subgroups were independently associated with lower BMI, lower education level, and higher PSQI score (Table 5).

\section{Discussion}

Previous studies suggested that psychological distress is common in patients with FD $[4,5,11,12]$. However, the psychological factors associated with FD remain undefined. In this study, both PSQI and SCL-90R were applied to assess the sleeping and psychological conditions of patients with FD, analyzing the associations of sleep disturbance, somatization, obsessive-compulsive, interpersonal sensitivity, depression, anxiety, hostility, phobic anxiety, paranoid ideation and psychoticism with FD, respectively. We found that FD was associated with sleep disorder and several psychopathological factors (somatization, obsessivecompulsive, interpersonal sensitivity, depression, anxiety, hostility, phobic anxiety, psychoticism). In addition, we found that lower BMI, lower level of education, sleep disorder, hostility and phobic anxiety were independent risk factors for FD.

The associations of poor sleep with functional gastrointestinal disorders have been evaluated in previous physiological and epidemiological studies [6, 13-17]. However, whether sleep disturbance is independently associated with FD remains controversial. A previous study assessing 505 patients with functional gastrointestinal disorders and 247 healthy controls found that 68 and $50.2 \%$ of individuals with FD and irritable bowel syndrome (IBS), respectively, have sleep disturbance [15]. A study based on Rome III criteria for FD showed that FD symptoms are significantly correlated with sleep disturbance [6]. A community-based cohort study reported that sleep dysfunction and somatization are independent risk factors for dyspepsia [14]. A population-based research indicated that IBS is significantly more common in people with 
Table 3 SCL-90R scores in FD patients and healthy controls (mean \pm SD)

\begin{tabular}{|c|c|c|c|c|c|c|c|c|c|c|c|}
\hline Groups & Somatization & $\begin{array}{l}\text { Obsessive- } \\
\text { compulsive }\end{array}$ & $\begin{array}{l}\text { Interpersonal } \\
\text { sensitivity }\end{array}$ & Depression & Anxiety & Hostility & $\begin{array}{l}\text { Phobic } \\
\text { anxiety }\end{array}$ & $\begin{array}{l}\text { Paranoid } \\
\text { ideation }\end{array}$ & Psychoticism & $\begin{array}{l}\text { Additional } \\
\text { items }\end{array}$ & $\begin{array}{l}\text { Total } \\
\text { score }\end{array}$ \\
\hline$\overline{F D}$ & $1.75 \pm 0.74$ & $2.00 \pm 0.77$ & $1.81 \pm 0.82$ & $1.87 \pm 0.88$ & $1.78 \pm 0.83$ & $1.84 \pm 0.81$ & $1.53 \pm 0.83$ & $1.73 \pm 0.82$ & $1.63 \pm 0.70$ & $1.90 \pm 0.90$ & $162.00 \pm 66.26$ \\
\hline $\mathrm{HC}$ & $1.40 \pm 0.43$ & $1.75 \pm 0.56$ & $1.52 \pm 0.43$ & $1.53 \pm 0.54$ & $1.47 \pm 0.43$ & $1.52 \pm 0.61$ & $1.25 \pm 0.36$ & $1.55 \pm 0.55$ & $1.42 \pm 0.40$ & $1.58 \pm 0.56$ & $135.18 \pm 36.80$ \\
\hline$t$ & 3.960 & 2.485 & 3.026 & 3.146 & 3.212 & 3.018 & 3.155 & 1.738 & 2.536 & 2.911 & 3.452 \\
\hline$P$ & $<0.000^{*}$ & $0.014^{*}$ & $0.003^{*}$ & $0.002^{*}$ & $0.002^{*}$ & $0.003^{*}$ & $0.002^{*}$ & 0.084 & $0.012^{*}$ & 0.004 & $0.001^{*}$ \\
\hline
\end{tabular}

sleep disturbance, while its association with FD was not statistically significant [13]. In the present study, sleep disturbance was an independent risk factor for FD and both FD subgroups. In addition, PSQI scores were higher in FD patients with more severe symptoms, suggesting that impaired sleep may be an important factor affecting the severity of FD symptoms.

The mechanisms underlying mutual interactions between sleep disturbance and FD symptom expression may be quite complex. We hypothesized that on one hand, severe epigastric pain or burning may lead to disorders that initiate and maintain sleep; on the other hand, disrupted sleep could lead to increased symptom expression in patients with FD. In support of this hypothesis, a previous study demonstrated that both rapid eye movement (REM) sleep and slow wave sleep (SWS) interruption could decrease mechanical pain thresholds in healthy volunteers [18].

The role of adverse psychological factors in the development of functional gastrointestinal disorders (FGIDs) attracts increasing attention [19]. In a recent retrospective study, data of 4966 patients diagnosed with a FGID and 1002 randomly selected individuals indicated that twice as much patients are diagnosed with a mood disorder before an FGID; mood disorder was on average diagnosed more than 3 years before FGID [20]. As mentioned above, studies assessing the psychological factors that contribute to FD development are limited. In this study, SCL-90R was applied to assess mood condition, and the scores of 9 symptomatic dimensions, including somatization, obsessivecompulsive, interpersonal sensitivity, depression, anxiety, hostility, phobic anxiety, psychoticism and additional items, were markedly higher in patients with FD than in healthy controls. These findings demonstrated that negative emotions are common in patients with FD. Given the chronicity of symptoms in the current patient cohort, this is unsurprising because chronic disease status may cause increased prevalence of mood disorders. Further analysis of independent risk factors for FD indicated that hostility and phobic anxiety were independently associated with FD; subgroup analysis showed that hostility

Table 4 Univariate and multivariate logistic regression analysis of risk factors for FD

\begin{tabular}{|c|c|c|c|c|c|c|}
\hline \multirow[t]{2}{*}{ Variables } & \multicolumn{3}{|c|}{ Univariate analysis } & \multicolumn{3}{|c|}{ Multivariate analysis } \\
\hline & OR & $95 \% \mathrm{Cl}$ & $P$ & OR & $95 \% \mathrm{Cl}$ & $P$ \\
\hline Age & 1.004 & $0.978-1.030$ & 0.778 & - & - & - \\
\hline Gender & 1.096 & $0.498-2.413$ & 0.819 & - & - & - \\
\hline BMI & 0.749 & $0.646-0.868$ & $<0.001$ & 0.750 & $0.619-0.910$ & $0.004^{*}$ \\
\hline Years of education & 0.788 & $0.709-0.875$ & $<0.001$ & 0.771 & $0.669-0.888$ & $<0.001^{*}$ \\
\hline PSQI score & 1.451 & $1.276-1.649$ & $<0.001$ & 1.549 & $1.301-1.843$ & $<0.001^{*}$ \\
\hline SCL-90R score & 1.009 & $1.003-1.016$ & 0.006 & 0.963 & $0.866-1.070$ & 0.484 \\
\hline Somatization & 2.617 & $1.433-4.779$ & 0.002 & 4.365 & $0.603-31.623$ & 0.145 \\
\hline Obsessive-compulsive & 1.735 & $1.063-2.832$ & 0.027 & 1.260 & $0.181-8.765$ & 0.815 \\
\hline Interpersonal sensitivity & 1.910 & $1.133-3.219$ & 0.015 & 3.344 & $0.374-29.927$ & 0.280 \\
\hline Depression & 1.880 & $1.169-3.024$ & 0.009 & 4.362 & $0.347-54.826$ & 0.254 \\
\hline Anxiety & 2.041 & $1.179-3.536$ & 0.011 & 0.492 & $0.037-6.477$ & 0.590 \\
\hline Hostility & 1.953 & $1.187-3.212$ & 0.008 & 4.287 & $1.116-16.467$ & $0.034^{*}$ \\
\hline Phobic anxiety & 2.077 & $1.137-3.794$ & 0.017 & 6.411 & $1.396-29.433$ & $0.017^{*}$ \\
\hline Paranoid ideation & 1.427 & $0.904-2.252$ & 0.127 & - & - & - \\
\hline Psychoticism & 1.865 & $1.044-3.331$ & 0.035 & 0.147 & $0.021-1.004$ & 0.050 \\
\hline Additional items & 1.742 & $1.117-2.719$ & 0.014 & 0.349 & $0.094-1.292$ & 0.115 \\
\hline
\end{tabular}


Table 5 Multivariate logistic regression analysis of risk factors for FD subgroups

\begin{tabular}{|c|c|c|c|c|c|c|}
\hline \multirow[t]{2}{*}{ Variables } & \multicolumn{3}{|l|}{ EPS } & \multicolumn{3}{|l|}{ PDS } \\
\hline & $\overline{\mathrm{OR}}$ & $95 \% \mathrm{Cl}$ & $P$ & $\overline{\mathrm{OR}}$ & $95 \% \mathrm{Cl}$ & $P$ \\
\hline BMl & 0.768 & $0.625-0.944$ & $0.012^{*}$ & 0.560 & $0.406-0.771$ & $<0.001^{*}$ \\
\hline Years of education & 0.800 & $0.691-0.925$ & $0.003^{*}$ & 0.701 & $0.574-0.857$ & $0.001^{*}$ \\
\hline PSQI score & 1.531 & $1.287-1.822$ & $<0.001^{*}$ & 1.690 & $1.297-2.201$ & $<0.001^{*}$ \\
\hline SCL-90R score & 0.942 & $0.854-1.038$ & 0.227 & 0.832 & $0.578-1.197$ & 0.321 \\
\hline Somatization & 8.571 & $1.096-67.017$ & $0.041^{*}$ & 16.132 & $0.147-1771.600$ & 0.246 \\
\hline Obsessive-compulsive & 1.176 & $0.171-8.093$ & 0.869 & 2.566 & $0.047-139.886$ & 0.644 \\
\hline Interpersonal sensitivity & 3.813 & $0.391-37.185$ & 0.249 & 50.783 & $0.755-3415.805$ & 0.067 \\
\hline Depression & 2.789 & $0.212-36.660$ & 0.435 & 110.215 & $0.408-29,799.742$ & 0.100 \\
\hline Anxiety & 1.709 & $0.148-19.761$ & 0.668 & 0.462 & $0.003-72.625$ & 0.765 \\
\hline Hostility & 3.722 & $1.005-13.792$ & $0.049^{*}$ & 16.826 & $1.093-259.051$ & $0.043^{*}$ \\
\hline Phobic anxiety & 3.534 & $0.906-13.783$ & 0.069 & 14.084 & $0.575-344.787$ & 0.105 \\
\hline Paranoid ideation & - & - & - & 0.843 & $0.029-24.241$ & 0.920 \\
\hline Psychoticism & - & - & - & 2.939 & $0.051-170.797$ & 0.603 \\
\hline Additional items & 0.241 & $0.074-0.786$ & $0.018^{*}$ & 0.990 & $0.066-14.862$ & 0.994 \\
\hline
\end{tabular}

was an independent risk factor for both FD subgroups, while somatization and additional psychiatric symptoms predicted EPS.

With respect to clinical application, whether treating FD patients with sleep or psychotherapeutic medications improves dyspeptic symptoms remains unclear. Related data are limited, as only few randomized controlled trials have been conducted for FD psychotherapy [21, 22]. A systematic review assessing the effects of psychotherapy on dyspepsia symptoms was withdrawn because only four trials were eligible [5]. Nevertheless, all four trials suggested that psychological interventions benefit dyspepsia symptoms [21]. A 6-month-follow-up randomized controlled trial reported that adding psychotherapy to standard medical therapy improves short- and long-term curative effects [22]. In a recent randomized, placebo-controlled trial, treating FD patients with mirtazapine was shown to significantly improve early satiation, the quality of life, gastrointestinal-specific anxiety, nutrient tolerance, and weight loss [23].

This is a cross-disciplinary research spanning gastroenterology and psychology. We focused on evaluating sleep quality and mood symptoms in Chinese patients with FD, with a view to compare with other racial population in future. It is helpful for clinicians to pay more attention to the sleep disturbance and psychological factors of FD patients and to provide more effective treatments for them.

The present study had several limitations. For example, no physiological measurements were used in this study, although the diagnosis of sleep disturbance is still largely dependent on patient's subjective feelings and symptoms.

\section{Conclusions}

In conclusion, this study demonstrated that sleep disturbance and negative emotions were common in patients with FD. Impaired sleep was an independent risk factor for FD and both FD subgroups, and may play a role in symptom expression. Hostility and phobic anxiety were independently associated with FD development. We further demonstrated that hostility was an independent risk factor for both FD subgroups, while somatization and additional psychiatric symptoms predicted EPS. Further exploration of the mechanisms linking sleep disturbance and negative emotions with FD may yield new approaches to interventions that reduce FD symptoms.

\section{Abbreviations}

BMI: Body mass index; EPS: Epigastric pain syndrome; FD: Functional dyspepsia; FGIDs: Functional gastrointestinal disorders; IBS: Irritable bowel syndrome; PDS: Postprandial distress syndrome; PSQI: Pittsburgh Sleep Quality Index; REM: Rapid eye movement; SCL-90R: Symptom Checklist-90-Revised; SWS: Slow wave sleep

\section{Funding}

This study was supported by Administration of Traditional Chinese Medicine of Jiangsu Province, China (Grant No.YB2015163) and the Research

Foundation of Jiangsu provincial commission of health and family planning (Grant No.Y2015052). The funders had no role in the design of the study and collection, analysis, and interpretation of data and in writing the manuscript.

\section{Availability of data and materials}

The datasets used and/or analysed during the current study are available from the corresponding author on reasonable request.

\section{Authors' contributions}

$Y L$, with help of MW, planned the present study's content and analysis, interpreted the data and wrote the paper. LL helped in the conception of the study's aim and content, together with YG were responsible for the diagnosis of FD. YL, YG, DH, YHL, YW, HW, XC initiated and performed the 
whole survey, analysed the data and helped to interpret the findings and to write the paper. All authors have read and approved the final manuscript.

\section{Ethics approval and consent to participate}

This study was approved by the Ethics Committee of First Affiliated Hospital of Nanjing Medical University, and conducted according to the Declaration of Helsinki. Written informed consents were obtained from all participants.

\section{Competing interests}

The authors declare that they have no competing interests.

\section{Publisher's Note}

Springer Nature remains neutral with regard to jurisdictional claims in published maps and institutional affiliations.

\section{Author details}

'Department of Psychiatry, the First Affiliated Hospital of Nanjing Medical University, Nanjing 210029, China. ²Department of Gastroenterology, the First Affiliated Hospital of Nanjing Medical University, Nanjing 210029, China. ${ }^{3}$ Department of Traditional Chinese Medicine, the First Affiliated Hospital of Nanjing Medical University, Nanjing 210029, China. ${ }^{4}$ Department of Psychiatry, Zhongda Hospital, Southeast University, Nanjing 210029, China.

Received: 7 February 2018 Accepted: 3 May 2018

Published online: 18 May 2018

\section{References}

1. Drossman DA. The functional gastrointestinal disorders and the Rome III process. Gastroenterol. 2006;130(5):1377-90.

2. Fang YJ, Liou JM, Chen CC, Lee JY, Hsu YC, Chen MJ, Tseng PH, Chang CY, Yang $\mathrm{TH}$, Chang WH, et al. Distinct aetiopathogenesis in subgroups of functional dyspepsia according to the Rome III criteria. Gut. 2015;64(10): 1517-28.

3. Miwa H, Ghoshal UC, Gonlachanvit S, Gwee KA, Ang TL, Chang FY, Fock KM, Hongo $\mathrm{M}$, Hou $\mathrm{X}$, Kachintorn $U$, et al. Asian consensus report on functional dyspepsia. J Neurogastroenterol Motil. 2012;18(2):150-68.

4. Aro P, Talley NJ, Johansson SE, Agreus L, Ronkainen J. Anxiety is linked to new-onset dyspepsia in the Swedish population - a 10 year follow-up Study. Gastroenterology. 2015;148(5):928-37.

5. Hsu YC, Liou JM, Liao SC, Yang TH, Wu HT, Hsu WL, Lin HJ, Wang HP, Wu MS Psychopathology and personality trait in subgroups of functional dyspepsia based on Rome III criteria. Am J Gastroenterol. 2009;104(10):2534-42.

6. Lacy BE, Everhart K, Crowell MD. Functional dyspepsia is associated with sleep disorders. Clin Gastroenterol Hepatol. 2011:9(5):410-4.

7. Liu X, Tang M, Hu L, Wang A. Reliability and validity of the Pittsburgh sleep quality index (Chinese) chin. J Psychiatry. 1996;29(2):103-7.

8. Tang Q, Cheng Z, Yuan A, Deng Y. The use and reanalysis of SCL-90 in China (Chinese). Chinese J Clin Psychol. 1999;7:16-20.

9. Derogatis LR. Symptom Checklist-90-revised. In: Handbook of psychiatric measures. Washington, DC: American Psychiatric Association; 2000.

10. Tan H, Lan XM, Yu NL, Yang XC. Reliability and validity assessment of the revised symptom checklist 90 for alopecia areata patients in China. J Dermatol. 2015:42(10):975-80.

11. Mahadeva S, Yadav H, Rampal S, Goh KL. Risk factors associated with dyspepsia in a rural Asian population and its impact on quality of life. Am J Gastroenterol. 2010;105(4):904-12.

12. Jones MP, Maganti K. Symptoms, gastric function, and psychosocial factors in functional dyspepsia. J Clin Gastroenterol. 2004;38(10):866-72.

13. Vege SS, Locke GR 3rd, Weaver AL, Farmer SA, Melton LJ 3rd, Talley NJ. Functional gastrointestinal disorders among people with sleep disturbances: a population-based study. Mayo Clin Proc. 2004;79(12):1501-6.

14. Gathaiya N, Locke GR 3rd, Camilleri M, Schleck CD, Zinsmeister AR, Talley NJ. Novel associations with dyspepsia: a community-based study of familial aggregation, sleep dysfunction and somatization. Neurogastroenterol Motil. 2009;21(9):922-e969.

15. Fass R, Fullerton S, Tung S, Mayer EA. Sleep disturbances in clinic patients with functional bowel disorders. Am J Gastroenterol. 2000;95(5):1195-2000

16. Cremonini F, Camilleri M, Zinsmeister AR, Herrick LM, Beebe T, Talley NJ. Sleep disturbances are linked to both upper and lower gastrointestinal symptoms in the general population. Neurogastroenterol Motil. 2009;21(2): $128-35$.
17. Schurman JV, Friesen CA, Dai H, Danda CE, Hyman PE, Cocjin JT. Sleep problems and functional disability in children with functional gastrointestinal disorders: an examination of the potential mediating effects of physical and emotional symptoms. BMC Gastroenterol. 2012;12:142.

18. Onen SH, Alloui A, Gross A, Eschallier A, Dubray C. The effects of total sleep deprivation, selective sleep interruption and sleep recovery on pain tolerance thresholds in healthy subjects. J Sleep Res. 2001;10(1):35-42.

19. Locke GR 3rd, Weaver AL, Melton LJ 3rd, Talley NJ. Psychosocial factors are linked to functional gastrointestinal disorders: a population based nested case-control study. Am J Gastroenterol. 2004;99(2):350-7.

20. Jones MP, Tack J, Van Oudenhove L, Walker MM, Holtmann G, Koloski NA, Talley NJ. Mood and anxiety disorders precede development of functional gastrointestinal disorders in patients but not in the population. Clin Gastroenterol Hepatol. 2017;15(7):1014-1020 e1014.

21. Soo S, Moayyedi P, Deeks JJ, Delaney B, Lewis M, Forman D. WITHDRAWN: psychological interventions for non-ulcer dyspepsia. Cochrane Database Syst Rev. 2011;2:CD002301.

22. Orive M, Barrio I, Orive VM, Matellanes B, Padierna JA, Cabriada J, Orive A, Escobar A, Quintana JM. A randomized controlled trial of a 10week group psychotherapeutic treatment added to standard medical treatment in patients with functional dyspepsia. J Psychosom Res. 2015;78(6):563-8,

23. Tack J, Ly HG, Carbone F, Vanheel H, Vanuytsel T, Holvoet L, Boeckxstaens G, Caenepeel P, Arts J, Van Oudenhove L. Efficacy of mirtazapine in patients with functional dyspepsia and weight loss. Clin Gastroenterol Hepatol. 2016 14(3):385-92. e384

\section{Ready to submit your research? Choose BMC and benefit from:}

- fast, convenient online submission

- thorough peer review by experienced researchers in your field

- rapid publication on acceptance

- support for research data, including large and complex data types

- gold Open Access which fosters wider collaboration and increased citations

- maximum visibility for your research: over $100 \mathrm{M}$ website views per year

At BMC, research is always in progress.

Learn more biomedcentral.com/submissions 